\title{
Cryptococcus Antigen Measurement
}

National Cancer Institute

\section{Source}

National Cancer Institute. Cryptococcus Antigen Measurement. NCI Thesaurus. Code C154829.

The determination of the Cryptococcus antigen present in a sample. 